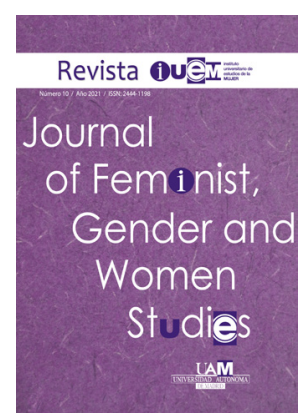

\section{La construcción de la normalidad en la sexualidad contemporánea}

\author{
The construction of normality in contemporary sexuality
}

Clara Soto Heredero ${ }^{1, @ ~}$

${ }^{1}$ Universidad Complutense de Madrid.

$@$ Autor/a de correspondencia: clasoto@ucm.es

\title{
Resumen
}

En el presente artículo se realiza una genealogía crítica de la sexualidad. Este asunto es el punto de partida para reflexionar acerca de cómo se está construyendo el imaginario colectivo sexual en la actualidad y cuáles son los aparatos de verificación que lo están legitimando. Partiendo del análisis de la obra Michel Foucault, principalmente de 'Historia de la sexualidad', por Judith Butler y Paul B. Preciado, entre otros; se busca la arqueología de la normalidad en el ámbito de la sexualidad, sus límites y hasta qué punto este concepto es una realidad puramente biológica o una construcción social.

En base a lo anteriormente expuesto, este trabajo se sitúa en el contexto del postporno, como un espacio político y filosófico en el que realizar una exploración profunda sobre el género, el sexo, la sexualidad y la representación sexual. Un espacio libre en el que se pueden cuestionar, trabajar y reestructurar estos términos.

Palabras clave: Sexualidad, normalidad, post-porno, feminismo, Teoría Queer.

\begin{abstract}
In the present study a critical genealogy of sexuality is carried out. This issue is the starting point to reflect on how the sexual imaginary is currently being constructed and which are the verification devices that are legitimizing it. Based on the analysis of the Michel Foucault's work, mainly from 'History of sexuality', conducted by Judith Butler and Paul B. Preciado, among others; the archeology of normality is sought in the field of sexuality, seeking it's limits and wondering what extent this concept is a purely biological reality or a social construction.

In the light of the above, this work is placed in the context of postporno, as a political and philosophical space in which is possible to make a deep exploration of gender, sex, sexuality and sexual representation. A free space to question, work and restructure these concepts.
\end{abstract}

Keywords: Sexuality, normality, post-porn. Feminism, Queer Theory. 


\section{INTRODUCCIÓN}

En la presente investigación se establece como objeto de estudio la construcción de la normalidad en la sexualidad contemporánea. Estas dos nociones, normalidad y sexualidad, son dos grandes campos que se relacionan horizontalmente. Lo que interesa, por tanto, es reflexionar acerca de los puntos de encuentro existentes entre ambos y cómo se condicionan entre sí.

A continuación se realiza una toma de posición inicial de estos conceptos con el fin de situar un punto de partida teórico. Respecto a la sexualidad, la OMS la define como: "Un aspecto central del ser humano, presente a lo largo de su vida. Abarca al sexo, las identidades y los papeles de género, el erotismo, el placer, la intimidad, la reproducción y la orientación sexual. Se vivencia y se expresa a través de pensamientos, fantasías, deseos, creencias, actitudes, valores, conductas, prácticas, papeles y relaciones interpersonales" (OMS, 2006).

Aunque se tiene constancia de este concepto desde mediados del siglo XIX, en el presente trabajo de investigación se acota cronológicamente el objeto de estudio partiendo desde la segunda mitad del siglo XX. Esto se debe fundamentalmente a dos hechos que se consideran cruciales. El primero de ellos es la comercialización de la primera píldora anticonceptiva en 1954. Gracias a este microdispositivo biopolítico ${ }^{1}$ la fertilidad de las mujeres empieza a depender de ellas mismas y cambia el paradigma que unía irremediablemente el sexo con la reproducción. El segundo hecho se sitúa en la década de los setenta con la publicación por parte de Michael Foucault de 'Historia de la Sexualidad', donde plantea por primera vez que la sexualidad no es un elemento natural universal humano que se ha intentado reprimir a lo largo de la historia, sino una construcción social en sí misma. En este periodo cabe destacar también la realización de dos estudios complejos acerca de la sexualidad: 'Comportamiento sexual en el hombre' (Kinsey, 1948) y 'Respuesta sexual humana' (Masters y Johnson, 1966).

Respecto a la noción de normalidad, a lo largo de la investigación se observa que la evolución de la noción de sexualidad está condicionada por la construcción paralela de una serie de modelos ejemplares. Volviendo a la obra de Michael Foucault, desde lo que este autor denominó aparatos de verificación se producen modelos de subjetividad y los movimientos de resistencia los cuestionan, intentando ampliarlos, despedazarlos, deconstruirlos. Lo que ambos sistemas de producción de subjetividades tienen en común es que construyen, bien por afirmación o por oposición, una verdad de lo sexual que se verá traducida en modelos sociales

\footnotetext{
1 Concepto extraído de la obra de Michael Foucault que se define como el poder que ejerce un gobierno a través de los cuerpos. La primera definición de este término aparece su obra Historia de la sexualidad como: "Concretamente, ese poder sobre la vida se desarrolló desde el siglo XVII en dos formas principales; [...] El segundo, formado algo más tarde, hacia mediados del siglo XVIII, fue centrado en el cuerpo-especie, en el cuerpo transido por la mecánica de lo viviente y que sirve de soporte a los procesos biológicos: la proliferación, los nacimientos y la mortalidad, el nivel de salud, la duración de la vida y la longevidad, con todas las condiciones que pueden hacerlos variar; todos esos problemas los toma a su cargo una serie de intervenciones y controles reguladores: una biopolítica de la población." (Foucault, 1991).
}

de conducta. En definitiva, esta verdad de lo sexual no deja de ser un tipo de normatividad que está en constante crisis, produciendo cuerpos abyectos que se rebelan y luchan por cuestionar dicha normalidad. Cabe entonces cuestionarse qué saberes se han desarrollado en torno a la sexualidad, qué sistemas de poder regulan sus prácticas y qué estructuras funcionan como normas para los sujetos sexuales.

En la primera acepción de la definición de 'normal' de la RAE, este concepto se relaciona con la naturaleza. Esto se debe a que 'lo natural' ha servido desde la llustración para justificar una gran cantidad de acciones humanas. Donna Haraway afirma: "La naturaleza, contraste de la cultura, es zona de coacciones, de lo dado y de la materia como recurso. La naturaleza es la materia prima necesaria para la acción humana, el campo de la imposición de la voluntad y el corolario de la mente. También ha servido como modelo para la acción humana, como poderosa base del discurso moral. Ser innatural, o actuar de manera no natural, no se ha considerado como saludable, moral, legal o, en general, como una buena idea." (Haraway, 2004: 102).

La idea de lo natural aparecerá discursivamente para reforzar las conductas heteronormativas como únicas, legítimas y verdaderas; también se utilizará como argumento para penalizar sexualidades y relaciones no convencionales. En este sentido, David Córdoba afirma: "Veremos reproducida esta ambigüedad discursiva en relación a la sexualidad: de un lado, es lo más animal y cercano al orden natural que hay en el ser humano ( $y$, por lo tanto, debe ser controlada para mantener el orden social, que de otra forma se vería en peligro); pero, por otro lado, la naturaleza se introducirá como elemento en la argumentación con la función de ligar la sexualidad a la reproducción como su única forma legítima" (Córdoba, 2005: 25).

Continuando el razonamiento de David Córdoba, se parte de la separación entre naturaleza y sexualidad (entendiendo como naturaleza todo aquello relacionado con la dimensión biológica de la existencia), estableciendo que la sexualidad se construye socialmente. Esta ruptura epistemológica que ahora puede llegar a parecer muy evidente, es el resultado de un proceso largo y complejo que se inició con la aparición del psicoanálisis y que se estudiará con mayor profundidad en el análisis teórico.

Para realizar un análisis profundo de la sexualidad contemporánea, es necesaria una revisión previa de conceptos. Una exploración de una serie de axiomas que han llegado a la actualidad sin un cuestionamiento crítico, escondidos en el inconsciente colectivo como verdades universales.

El primero de ellos, y quizá el más importante, es el esencialismo sexual ${ }^{2}$. La concepción de que el sexo y sus prácticas responden a una necesidad puramente biológica e incontrolable proviene de la tradición católica en la que se relaciona el deseo sexual con el pecado y de esta manera se interpreta como una pulsión irremediable. Esto se verá justificado, perpetuado y reproducido por las instituciones científicas como la biología, la medicina, la psiquiatría y la psicología. Esta desvinculación del deseo y el contexto

\footnotetext{
2 Se toma la noción de esencialismo sexual de Gayle Rubin: "Ia idea de que el sexo es una fuerza natural que existe con anterioridad a la vida social y que da forma a instituciones." (Rubin, 1989: 126).
} 
social impide la correcta percepción de las relaciones de poder, las violencias y las discriminaciones que se producen en las conductas sexuales. Es importante establecer que la sexualidad y todas sus manifestaciones son producto de la construcción social y que, por lo tanto, dependen del contexto en el que se producen.

De esta forma, esta investigación se sitúa en el constructivismo sexual que, en contraposición al esencialismo, considera que "Ia sexualidad se constituye en la sociedad y en la historia y que no está unívocamente determinada por la biología" (Rubin, 1989: 128).

Otra idea que se considera necesaria cuestionar es la existencia de una única sexualidad ejemplar. En 1989 Gayle Rubin dice: "Es difícil desarrollar una ética sexual pluralista sin un concepto de variedad sexual benigna. [...] Una de las ideas más tenaces sobre el sexo es que hay una forma de hacerlo mejor que todas las demás, y que todo el mundo debería practicarlo en dicha forma." (Rubin, 1989: 136)

En líneas generales podría concluirse que la sexualidad es una parte fundamental de la vida de cualquier persona a lo largo de su existencia, desde el nacimiento hasta la muerte. Es un campo que se ha estudiado ampliamente desde múltiples disciplinas y que se ha cuestionado desde otros tantos movimientos de resistencia a lo largo de los siglos XX y XXI, lo que convierte esta área de conocimiento en una de las grandes preocupaciones de la contemporaneidad. Esta noción, que a priori puede parecer un tema poco importante comparada con otras, en realidad es un fiel reflejo de cómo se construye la sociedad. La gestión de los placeres determina en gran medida la evolución de estructuras sociales como la familia, y a su vez influye en el desarrollo de sistemas de biopoder ${ }^{3}$.

De esta manera el principal objetivo del artículo será realizar una genealogía de la sexualidad. Para llevar esto acabo es necesario establecer que la sexualidad es un hecho construido socialmente $y$, por lo tanto, reflexionar cómo se percibe actualmente la sexualidad y qué aparatos de verificación la legitiman.

\section{METOdOLOGÍA}

Respecto a la metodología realizada en este artículo, se ha evitado una perspectiva historicista lineal intentando dar cabida a puntos de vista que no han aparecido en las narraciones hegemónicas. Intentando ser coherentes con esta idea se ha intentado trabajar con el planteamiento de genealogía de Michael Foucault, siguiendo el trabajo de Nietzsche. Dicho autor define la genealogía de la siguiente manera: "Hacer la genealogía de los valores, de la moral, del ascetismo, del conocimiento no será por tanto partir a la búsqueda de su "origen», minusvalorando como inaccesibles todos los episodios de la historia; será por el contrario

\footnotetext{
3 Concepto foulcaltiano que aparece por primera vez en Historia de la Sexualidad definido de la siguiente manera: "La vieja potencia de la muerte, en la cual se simbolizaba el poder soberano, se halla ahora cuidadosamente recubierta por la administración de los cuerpos y la gestión calculadora de la vida. Desarrollo rápido durante la edad clásica de diversas disciplinas -escuelas, colegios, cuarteles, talleres; aparición también, en el campo de las prácticas políticas y las observaciones económicas, de los problemas de natalidad, longevidad, salud pública, vivienda, migración; explosión, pues, de técnicas diversas y numerosas para obtener la sujeción de los cuerpos y el control de las poblaciones." (Foucault, 1991:84).
}

ocuparse en las meticulosidades y en los azares de los comienzos; prestar una escrupulosa atención a su derrisoria malevolencia; prestarse a verlas surgir quitadas las máscaras, con el rostro del otro; no tener pudor para ir a buscarlas allí donde están "revolviendo los bajos fondos», dejarles el tiempo para remontar el laberinto en el que ninguna verdad nunca jamás las ha mantenido bajo su protección". (Foucault, 1988: 3). Esta preocupación por tratar de dar relevancia a todos los puntos de vista posibles se considera especialmente importante en el desarrollo de este artículo dado que las nociones que estructuran el mismo, sexualidad y normalidad, forman parte del ideario político de colectivos que históricamente han sido invisibilizados.

\section{ANÁLISIS}

\section{Análisis del contexto}

Dado que en las últimas décadas han tenido lugar una gran cantidad de cambios como consecuencia de la revolución tecnológica: la aparición de Internet y las tecnologías de la comunicación, la invención de las redes sociales, la expansión de las imágenes y su dominio; cabe preguntarse cómo todos estos progresos han realizado un impacto irreversible en las relaciones interpersonales. Así, los vínculos emocionales se construyen de una manera radicalmente diferente a cómo se hacía hace cincuenta años, y esto sigue cambiando a una velocidad vertiginosa a día de hoy. Uno de los aspectos en los que esto más ha influido es la sexualidad y la construcción de las relaciones sexo-afectivas. En este sentido es importante cuestionarse si se está realizando una reflexión crítica de estos cambios y si, consecuentemente, se está haciendo un esfuerzo por educar a las generaciones venideras que, a fin de cuentas, serán la sociedad de un futuro próximo.

Antes de proseguir con lo que se podría llamar esta genealogía de la sexualidad contemporánea es necesaria una descripción, aunque sea esquemática, de la sociedad en la que nos vemos inmersos actualmente. También se considera imprescindible el estudio preliminar de una serie de nociones que aparecerán implícitamente a lo largo de la investigación.

A continuación se realiza un análisis epidérmico de la sociedad actual con el que se pretende explicar, de manera esquemática, cómo los límites de la mercantilización se han ampliado hasta desaparecer. Para ello es necesario situarla en el sistema económico capitalista financiero. Es importante la matización de financiero, porque caracteriza una manera muy contemporánea de generar plusvalía. Esto hace referencia a la especulación, es decir, multiplicar una cantidad de dinero ficticio sin necesidad de una acción productiva material. Más allá de su aspecto económico, este tipo de transacción demuestra una ambición generalizada de nuestra sociedad, conseguir un beneficio real a partir de acciones ficticias $y$, sobre todo, no productivas. Conseguir dinero sin tener dinero, esta situación se produce en un contexto que Jean Baudrillard definió como hiperrealidad en su ensayo 'La Precesión de los simulacros'. Este autor, aludiendo a la obra 'El Rigor de la Ciencia' de Jorge Luis Borges, comenta lo siguiente: "Hoy en día, la abstracción ya no es la del mapa, la del doble, la del espejo o la del concepto. La simulación no corresponde a un territorio, a una referencia, a una sustancia, sino que es la generación por los modelos de algo real sin origen ni 
realidad: lo hiperreal. El territorio ya no precede al mapa ni le sobrevive. En adelante será el mapa el que preceda al territorio -Precesión de los simulacros- y el que lo engendre, y si fuera preciso retomar la fábula, hoy serían los jirones del territorio los que se pudrirían lentamente sobre la superficie del mapa." (Baudrillard, 1977:4). Siguiendo el razonamiento anterior, podría decirse que la riqueza precede a la posesión de dinero. El simulacro se construye entre la realidad y la imagen, y es esa densidad que se interpone entre ellas. Al principio es apenas palpable, pero la imagen como signo deja de tener sentido a medida que se separa de la realidad. La distancia crece y se crea el simulacro. En la antigüedad la imagen llegó a ser tan perfecta como la realidad, con el tiempo se emancipó y se desarrolló al margen; y ahora es la realidad la que intenta desesperadamente imitar a las imágenes. Ya, en 1970, Baudrillard denominaba a la sociedad actual como la sociedad del consumo -de imágenes-. Según este autor: "el consumo generalizado de imágenes, de datos, de informaciones, también apunta a conjurar lo real en los signos de lo real, a conjurar la historia en los signos del cambio, etc... Consumimos lo real por anticipación o retrospectivamente, de todos modos a distancia, la distancia del signo. [...] Lo que caracteriza la sociedad de consumo es la universalidad de las crónicas de los medios de comunicación masiva. Toda la información, política, histórica, cultural, adquiere la misma forma, a la vez anodina y milagrosa, de las noticias cotidianas. La información se presenta completamente actualizada, vale decir, dramatizada a la manera de un espectáculo y completamente desactualizada, o sea, distanciada por el medio de comunicación y reducida a signos. La crónica de actualidad no es pues una categoría entre otras, sino que es la categoría cardinal de nuestro pensamiento mágico, de nuestra mitología." (Baudrillard, 1970:14).

Desde la proliferación de la fotografía, debido a la multiplicación de símbolos y al exceso de imágenes en el que la sociedad se ve inmersa, ha tenido lugar un entumecimiento, por llamarlo de algún modo, de la sensibilidad. Se han visto tantas cosas que ya no sorprende nada. La sociedad está completamente inmunizada ante la visión de la violencia. Ya sólo el hecho de digerir viendo un telediario cualquiera de principio a fin, la representación morbosa de todas la tragedias acontecidas a lo largo de todo el planeta, lo demuestra. En este sentido Susan Sontang apunta: "Las fotografías causan impacto en tanto que muestran algo novedoso. Infortunadamente el incremento del riesgo no cesa; en parte a causa de la proliferación misma de tales imágenes de horror. [...] Sufrir es una cosa; otra es convivir con las imágenes fotográficas del sufrimiento, que no necesariamente fortifican la conciencia ni la capacidad de compasión. También pueden corromperlas. Una vez que se han visto tales imágenes, se recorre la pendiente de ver más. Y más. Las imágenes pasman. Las imágenes anestesian". Esta autora mantiene que está teniendo lugar una estetización de la realidad que genera una distancia entre las imágenes y los hechos, y que contribuye a una desvinculación con los sucesos que se perciben a través del medio visual a no ser, matiza, que se haga un esfuerzo por ello. En palabras de la autora: "Lo que determina la posibilidad de ser afectado moralmente por fotografías es la existencia de una conciencia política relevante. Sin política, las fotografías del matadero de la historia simplemente se vivirán, con toda probabilidad, como irreales o como golpes emocionales desmoralizadores." (Sontag, 1973:38).

El nivel de violencia subjetiva ${ }^{4}$ a la que nos vemos expuestos es tal, que hace que todas las violencias objetivas, que son más graves y más abundantes, pasen desapercibidas a nuestros ojos.

Continuando con el análisis del panorama actual, se podría afirmar que vivimos en un mundo de cambios inminentes, de producción masiva de novedades, de actualización constante. La hiperconectividad nos lleva a un estado continuo de alerta, de crisis. Zygmunt Bauman, en este sentido, nos sitúa en la liquidez, a la que define como: "La sociedad moderna líquida es aquella en que las condiciones de actuación de sus miembros cambian antes que las formas de actuar se consoliden en unos hábitos y en una rutina determinadas" (Bauman, 2006:9).

Un entorno en el que la construcción de la identidad es cada vez más compleja, en el que nos vemos obligados a flexibilizarnos y adaptarnos a cada situación o, de lo contrario, seremos desechados y reemplazados como cualquier otro producto.

Llevando el concepto de liquidez al extremo, Alberto Royo revisando a Bauman expresa: "La misma cultura ha dejado de ser un conjunto consolidado de saberes para pasar a rendirse a la fugacidad y, finalmente, a la vaporosidad. La inmediatez, la búsqueda de la rentabilidad, la falta de exigencia y autoexigencia, el desprecio de la tradición, la obsesión innovadora, el consumismo, la educación placebo, el arrinconamiento de las humanidades y de la filosofía, la autoayuda, la mediocridad asumida y la ignorancia satisfecha hacen tambalearse aquello que era más consistente. [...] Lo hacemos por comodidad, por afán de consuelo, en una sociedad en la que reina lo vacío, lo intrascendente, lo voluble, lo trivial. Una sociedad gaseosa" (Royo, 2017:5).

Una sociedad gaseosa avalada por un sistema capitalista que hace tiempo que dejó de ser un sistema, para convertirse en una forma de vida. Hemos dejado atrás los días en los que era fácil distinguir qué se vendía. Hoy en día todo es susceptible de ser vendido y de ser comprado. Vemos, sin un ápice de asombro, un anuncio de un coche en el que no aparece ninguna imagen del vehículo que se vende. Esto tiene sentido porque, inconscientemente, lo que el consumidor ambiciona obtener de la compra de ese producto no es un medio de transporte, sino una pieza más para el rompecabezas de su identidad. Una herramienta para seguir desarrollando su supuesta unicidad.

En este sentido, las redes sociales nos han brindado una capacidad incuantificable de expresión personal. Han facilitado, también, la conexión entre personas que en otra época hubieran estado aisladas por sus gustos o preferencias. Bauman, en una entrevista que realizó para el periódico El País, intenta prevenir sobre lo que él define como una trampa.

\footnotetext{
4 Se parte de la obra Sobre la violencia de Slavoj Zizek, en la que define la violencia y establece una distinción entre violencias objetiva y subjetiva. En sus propias palabras. "29"La violencia subjetiva es simplemente la parte más visible de un triunvirato que incluye también dos tipos objetivos de violencia. En primer lugar, hay una violencia <<simbólica>> encarnada en el lenguaje y sus formas [...] En segundo lugar, existe otra a la que llamo <<sistémica >>, que son las consecuencias a menudo catastróficas del funcionamiento homogéneo de nuestros sistemas económico y político." (Zizek, 2008: 10).
} 
Según este sociólogo en las redes sociales se desarrolla una sensación falsa de comunicación ya que, en realidad, no son necesarias las habilidades sociales para poder participar. Esto se debe, a que gracias a la gran diversificación existente en la red es posible interactuar sin salir de la zona de confort, sin que exista un contraste real, debido a la endogamia que se puede llegar a producir.

El mismo apunta: "La diferencia entre la comunidad y la red es que tú perteneces a la comunidad pero la red te pertenece a ti. Puedes añadir amigos y puedes borrarlos, controlas a la gente con la que te relacionadas. La gente se siente un poco mejor porque la soledad es la gran amenaza en estos tiempos de individualización. Pero en las redes es tan fácil añadir amigos o borrarlos que no necesitas habilidades sociales." (Querol, 2016).

Es quizá necesario matizar que no es que las habilidades sociales ya no sean necesarias, sino que los propósitos de las mismas han cambiado. La sociabilización actual ha tomado una nueva forma, en la que su faceta expositiva es la más importante. Ya no vale con disfrutar de relaciones, además tiene que figurar en algún sitio. En este sentido Guy Debord escribió en 1967 'La sociedad del espectáculo', obra en la que describe cómo en la actualidad la representación ha sustituido a la acción convirtiéndose todo en un mero espectáculo, y que podría resumirse vastamente en el siguiente enunciamiento: "El espectáculo no es un conjunto de imágenes, sino una relación social entre personas mediatizada por imágenes" (Debord, 1967:5). Afirma que las relaciones entre mercancías han colonizado la vida social por completo, suplantando las relaciones entre personas y describe cómo el ser ha evolucionado en tener, y a su vez tener ha evolucionado simplemente en aparentar. Esto último se ve perfectamente reflejado en el slogan que utilizó la marca de relojes Viceroy desde 2006 hasta 2015: "No es lo que tengo, es lo que soy".

En definitiva, nos encontramos ante un panorama siempre cambiante del que es difícil intuir predicciones. La generación millenial se avalanza sobre nosotros y no la entendemos. Esos jóvenes vagan perdidos con demasiadas expectativas e incapaces de discriminar opciones, como dice Bauman "ante la visión del cambio atrapados entre el deseo y el miedo, entre la anticipación y la incertidumbre" (Bauman, 2007:45).

En el presente trabajo de investigación se plantea la hipótesis ¿cómo afecta todo esto a la sexualidad? ¿Qué está pasando en este ámbito en la actualidad?

\section{Análisis teórico}

En este epígrafe se realiza un estudio crítico de los principales pensadores que han desarrollado estudios sobre la sexualidad en su obra.

\section{Michael Foucault y el primer cambio de paradigma}

El primer gran cambio de paradigma conceptual que tiene lugar respecto al objeto de estudio se produce con la publicación de 'Historia de la sexualidad. La Voluntad de Saber' de Michael Foucault. En esta obra el autor analiza cómo la sexualidad, al estar directamente unida a la reproducción, pasa de ser un asunto privado a una preocupación pública en el siglo XVIII y cómo el discurso teológico que había construido la iglesia alrededor del sexo a lo largo de la Edad Media se descompone, se disuelve y se resuelve desde otras múltiples disciplinas, como pueden ser la demografía, la medicina o la psicología. El sexo, que hasta ese momento se mantenía como un interés de carácter individual en el que, en todo caso, intervenía la religión a través del rito de la confesión; se convierte en una preocupación pública. De esta manera cualquier práctica sexual, por leve que sea, podía llegar a verse convertida, como señala el autor, en “(...) no sólo objeto de intolerancia colectiva sino de una acción judicial, de una intervención médica, de un examen clínico atento y de toda una elaboración teórica" (Foucault, 1991:21).

Esta proliferación de discursos alrededor del sexo, derivó en un aumento exponencial de normas e imposiciones en la vida sexual de los individuos, con el fin de regular y asegurar la población. Debido a esta continuidad estricta entre sexualidad y reproducción, todas las prácticas no reproductivas empezaron a considerarse patológicas; y se categorizaron, diagnosticaron y convirtieron en susceptibles de cura. Es más, las prácticas sexuales dejaron de ser independientes del individuo y empezaron a formar parte de su identidad. Tomemos el ejemplo de la homosexualidad. Hasta ese momento las prácticas homosexuales se englobaban dentro de la sodomía, junto con otras tantas prácticas que formaban parte del sistema penal. Sin embargo, a partir del siglo XIX el homosexual empieza a ser una forma de vida, una identidad que en el siglo XX se convertirá en una forma de consumo ${ }^{5}$.

En la misma época que surgió el término 'homosexualidad', en 1892, apareció por primera vez el término 'heterosexualidad' en un artículo sobre la perversión sexual publicado por el norteamericano James G. Kiernan (Katz, 2012:37). Esta noción nace por la necesidad de enunciar la orientación sexual "normal", frente a la "opuesta" o "invertida". La heterosexualidad se plantea desde este momento como un coto delimitado de salud y buenas conductas alrededor del que giran el resto de sexualidades periféricas, consideradas como inmorales, poco saludables o patológicas. Jonathan N. Katz parafraseando a Havelock Ellis apunta: "Una mini historia de las designaciones psiquiátricas de la <<sexualidad anormal>> sugiere cómo el que esos doctores de manera explícita especificaran $<<p e r v e r s i o ́ n$ sexual $\gg>$, favoreció sus teorías implícitas de una <<sexualidad normal>>" (Katz, 2012:85).

El psicoanálisis fue la primera disciplina que inició la ruptura de la dicotomía sexualidad/naturaleza. En 1905 Sigmund Freud publicó 'Tres ensayos sobre la sexualidad'. Estos textos causaron un gran revuelo en la comunidad científica y hoy en día se consideran de las aportaciones más relevantes de su obra. El autor puso en tela de juicio dos cuestiones importantes. La primera de ellas, fue ampliar el concepto de sexualidad más allá de su función de reproducción, relacionándola de esta manera con el placer, los impulsos, el deseo y la afectividad. El otro planteamiento novedoso fue determinar que la sexualidad se iniciaba mucho antes en la vida de los sujetos. Freud contempló actividades sexuales desde la más tierna infancia y no desde la pubertad

\footnotetext{
5 Es importante situar la aparición de este término en 1870. En relación a la evolución del término homosexualidad desde su aparición como patología a una herramienta constructora de identidades consultar: Foucault, 1991:28 y Weeks, 1998:38.
} 
como se consideraba hasta ese momento. En el primero de los tres ensayos, Freud realiza una taxonomía pormenorizada de lo que él llama desviaciones sexuales, entre las cuales está, por supuesto, la homosexualidad referida como inversión. Con esta clasificación de patologías, Freud no sólo determina una gran cantidad de sujetos susceptibles de ser tratados por la clínica, sino que también refuerza la idea de heterosexualidad como norma. En este sentido, Jonathan N. Katz apunta: "Las obras de Freud proporcionan al canon heterosexual algunos de sus textos intelectualmente más evolucionados y ambivalentes puesto que Freud sirve como un importante creador moderno del ahistórico modelo médico de la heterosexualidad y como un teórico subversivo de la construcción social de la heterosexualidad: su invención histórica. Sus teorías brindan el más intrincado respaldo a la norma heterosexual e importantes herramientas para desafiar el dominio heterosexual." (Katz, 2012:89).

Las publicaciones de Freud y de otros psicoanalistas, en las que se exponían los problemas sexuales abiertamente, hicieron posible que se desarrollase una atmósfera generalizada en la que la preocupación por la sexualidad tenía sentido. Esto se ve reflejado, en la realización en las décadas de los cincuenta y sesenta de dos estudios complejos acerca del comportamiento sexual humano. En relación con la dicotomía heterosexualidad/homosexualidad interesa especialmente el primero de ellos, 'El informe Kinsey'. Este estudio consta de más de 20.000 entrevistas personales realizadas a hombres y mujeres, cuyos resultados fueron publicados en dos volúmenes: Comportamiento sexual del hombre, en 1948, y Comportamiento sexual de la mujer, en 1953. Esta colección masiva de historias sexuales anónimas llevó a constatar que un gran número de prácticas; como la masturbación, los comportamientos homosexuales y la iniciación temprana de la sexualidad, que hasta ese momento se consideraban marginales o inmorales, eran mucho más frecuentes de lo que se pensaba. El sorprendente hallazgo de actividades homosexuales, más o menos, generalizadas le llevó a plantear lo que hoy se conoce como la 'Escala Kinsey', un mecanismo que pretende evitar la clasificación de la orientación sexual en términos binarios desarrollando un sistema gradual de siete puntos en el que los sujetos se pueden identificar dependiendo de las experiencias que hayan tenido o del momento de su vida en el que se encuentren.

La heterosexualidad como régimen político empezará a cuestionarse desde el feminismo lesbiano en la década de los ochenta, con autoras como Adrienne Rich y Monique Wittig. El hecho de que la heterosexualidad se interprete como un régimen político y no como una simple orientación sexual, les lleva a plantear la heterosexualidad como un sistema impuesto capaz de mantener la estructura económica y social de la familia. Un dispositivo que Gayle Rubin denominará sistema 'Sexo-género', y lo definirá como: "el conjunto de disposiciones por el que una sociedad transforma la sexualidad biológica en productos de la actividad humana, y en el cual se satisfacen esas necesidades humanas transformadas." (Rubin, 1986:97). Más adelante en el mismo capítulo, matiza: "Por otro lado, no podemos limitar el sistema sexual a la <<reproducción $\gg>$, ni en el sentido biológico del término ni en el social. Un sistema de sexo/género es simplemente el momento reproductivo de un "modo de producción". La formación de la identidad de género es un ejemplo de producción en el campo del sistema sexual y un sistema de sexo/género incluye mucho más que las "relaciones de procreación", la reproducción en sentido biológico." (Rubin, 1986:102).

\section{Diferenciación sexual y la aparición de la noción de género}

Para poder entender el concepto de sexo-género que plantea Rubin, es necesario estudiar previamente la noción de género, y para poder comprender la construcción social del género; es imprescindible el estudio de la aparición de la diferenciación sexual de hombres y mujeres. En La construcción del sexo, Thomas $W$. Laqueur realiza una genealogía de la construcción de la diferencia sexual en la que concluye que: "En otras palabras, se inventaron los dos sexos como nuevo fundamento para el género." (Laqueur, 1994:259).

Este autor sitúa dos sistemas de comprensión del sexo. El primero, que será vigente hasta el siglo XVII, es el sistema de sexo único; en el que se entiende la existencia de un único sexo, el masculino y una variación menos desarrollada del mismo que será el femenino. Esto repercutirá en el entendimiento de la distinción de hombre y mujer, tanto biológica como socialmente. "En el mundo del sexo único es precisamente donde resultaba más directo hablar de la biología de los dos sexos, porque estaba incorporada en la política del género, en la cultura. Ser hombre o mujer significaba tener un rango social, un lugar en la sociedad, asumir un rol cultural, no ser orgánicamente de uno u otro de dos sexos inconmensurables. En otras palabras, con anterioridad al siglo XVII, el sexo era todavía una categoría sociológica y no ontológica." (Laqueur, 1994:28). Sin embargo, a partir del siglo XVIII se desarrolla el modelo de dos sexos, presente hasta la actualidad. Este modelo se estructura situando en un polo el sexo masculino y en el contrario, y siempre definido como una comparación del primero, el sexo femenino. De esta manera se fundamentarán todas y cada una de las desigualdades sociales, económicas y políticas que existían entre hombres y mujeres en las diferencias biológicas. Paul B. Preciado, estudiando el mismo texto, concluye al respecto: "en el despertar de la modernidad y del capitalismo es preciso inventar una estética de la diferencia sexual porque la jerarquía política entre hombres y mujeres comienza a ser cuestionada. De este modo, la nueva verdad anatómica viene a operar aquí como legitimación de la organización política de lo social." (Preciado, 2008:60).

A partir de la diferenciación de hombre/mujer, basada en la biología se establecen otras dos nociones: feminidad y masculinidad. Siguiendo el modelo de sexo único que plantea Laqueur, al considerar a las mujeres 'hechas de la misma materia' que los hombres, lo masculino y lo femenino no dejan de ser características que pueden referirse a ambos sexos. No existe una demanda social hacia las mujeres por ser femeninas o hacia los hombres por ser masculinos. Esto no quiere decir que no hubiese discriminación hacia las mujeres, sencillamente las razones de dicha discriminación se producían por otros motivos.

A partir del siglo XIX existe un esfuerzo generalizado por diferenciar las características femeninas y masculinas en todos los ámbitos, más allá de la anatomía de sus órganos genitales. Es cuando a las nociones de feminidad y 
masculinidad, empiezan a tener las connotaciones actuales y es importante remarcar que estas diferencias entre sexos, estarán justificadas, como decíamos antes, en la diferencia sexual biológica.

Esta relación entre feminidad/masculinidad y sexo biológico, vuelve a cuestionarse en el psicoanálisis a principios del siglo XX cuando Freud plantea la noción de bisexualidad ${ }^{6}$.

Así, en 1968 Robert Stoller a partir de sus investigaciones relacionadas con personas transexuales, habla por primera vez de 'identidad de género': "Género es un término que tiene más connotaciones psicológicas y culturales que biológicas. Si los términos apropiados para sexo son macho (male) y hembra (female), los términos correspondientes para género son masculino y femenino, términos que son totalmente independientes del sexo (biológico). Género es el grado de masculinidad o feminidad encontrado en una persona, y, obviamente, aunque los encontramos mezclados en los humanos, el hombre normal tiene una predominancia de masculinidad y la mujer normal una predominancia de feminidad. La identidad de género comienza con el conocimiento y el descubrimiento, ya sea consciente o inconsciente, de que alguien pertenece a un sexo y no al otro; conforme alguien se desarrolla, la identidad de género llega a ser mucho más complicada, de tal manera que, por ejemplo, alguien puede sentirse a sí mismo, no solamente como un hombre, sino un hombre masculino o un hombre afeminado o un hombre que fantasea con que es una mujer." (Stoller, 1968:10). Como dice Stoller, la identidad de género se desarrolla a lo largo de la vida del sujeto a partir de la identificación con un sexo, que no tiene por qué coincidir con el biológico. De hecho, la evolución de dicha identidad depende en mayor medida del entorno que le rodea que de sus condiciones biológicas.

A pesar de que la feminidad y la masculinidad vuelven a desidentificarse con el sexo biológico, esto sucede dentro de un paradigma en el que lo femenino ya está establecido como inferior a lo masculino.

\section{La gestión política de la sexualidad femenina}

Cuando Laqueur empezó a escribir La construcción del sexo su intención era, en realidad, realizar una recapitulación de la historia del placer sexual femenino y su posible desaparición. Esta cuestión es fundamental para el entendimiento de la sexualidad contemporánea: ¿En qué momento los hombres y las mujeres dejaron de desear de la misma manera, con la misma intensidad o con la misma frecuencia? Al iniciar su investigación, este autor se dio cuenta de que la división entre deseo femenino y masculino, y las diferencias que hoy se aprecian como biológicas, aparecieron al mismo tiempo que el modelo de dos sexos: "Pronto descubrí que la desaparición del placer femenino en los informes médicos sobre la concepción tuvo lugar más o menos al mismo tiempo que el cuerpo femenino dejó de ser considerado como una versión menor del masculino (modelo de un solo sexo) para pasar a ser un opuesto de mucha menor entidad (modelo de dos sexos)." (Laqueur, 1994:10). Cuando el orgasmo femenino dejó de ser necesario, al igual que el del

6 Esta noción aparece por primera vez en Tres ensayos sobre la sexualidad definida de la siguiente manera: "Ia disposición bisexual dota al individuo tanto de centros cerebrales masculinos y femeninos cuanto de órganos sexuales somáticos." (Freud, 1905:14). hombre, para la concepción; perdió el sentido y esto llevo, incluso, a que dejase de considerarse su existencia.

El ejemplo más notable de cómo la sexualidad femenina se ha gestionado, más bien reprimido, desde la sociedad es la invención de histeria ${ }^{7}$. Existe constancia de esta supuesta patología desde la antigüedad, si bien la American Psychiatric Association eliminó el término en 1952. La histeria ha constituido a lo largo de toda la historia un cajón de sastre que explica una cantidad infinita de malestares físicos femeninos, desde la cefalea hasta la ceguera; cuya cura consistía en el masaje vaginal hasta el paroxismo histérico, que hoy se reconoce como orgasmo. Ya en el siglo II d.C. Galeno la definía como una enfermedad propia de mujeres especialmente pasionales que sufrían privación sexual. La sexualidad femenina, leída desde un prisma absolutamente androcentrista, resultaba inexplicable y demasiado compleja. La satisfacción del deseo femenino carecía de importancia, y fue desplazándose lentamente del ámbito privado al institucional científico. "Así se convirtió la tarea de aliviar los síntomas de excitación femenina en una tarea médica, que definía los orgasmos femeninos en condiciones clínicas como las crisis de una enfermedad, el paroxismo histérico. En efecto, los doctores heredaron la tarea de producir orgasmos en las mujeres porque era un trabajo que no quería hacer nadie. No hay señales de que los médicos hombres disfrutaran dando tratamientos de masajes pélvicos. Al contrario, esta élite masculina buscó todas las maneras de sustituir sus dedos por otros recursos, como las atenciones de los maridos, las manos de las matronas o algún mecanismo incansable e impersonal." (Maines, 2010:10).

La época victoriana el diagnóstico de histeria estaba absolutamente normalizado. Esto se debe principalmente a dos motivos. El primero es la altísima represión sexual que tuvo lugar en aquella época, especialmente hacia las mujeres. La segunda es que la histeria, al considerarse una enfermedad crónica fácilmente diagnosticable, constituía una fuente de ingresos fija y fácil para las clínicas. Es importante remarcar que los diversos procedimientos médicos que se aplicaban a la histérica, es decir, las diferentes formas que tenía el médico de masturbar a la paciente, en ningún caso se contemplaban como actos pertenecientes a la esfera de lo sexual. Una vez más, esto se debe a la consideración androcentrista del sexo en la que la única actividad sexual 'de verdad' es el coito. Citando a Rachel P. Maines: "Este enfoque androcéntrico, de hecho, escondía el carácter sexual de los tratamientos médicos con masaje. Como no había penetración, los creyentes en la hipótesis de que solo la penetración satisfacía a las mujeres podían argumentar que no ocurría nada sexual cuando las pacientes experimentaban un paroxismo histérico bajo tratamiento" (Maines, 2010:16). La crisis histérica o el paroxismo histérico, se consideró durante mucho tiempo un fenómeno similar a un ataque de epilepsia. El momento en el que se volvió a considerar que las mujeres también tienen capacidad de llegar al orgasmo es incierto.

El placer de la mujer, como se ha argumentado extensamente, se ha denostado a lo largo de la historia hasta casi extinguirlo. Se ha culpabilizado y reprimido hasta el punto de considerarse peligroso para la salud y para la sociedad.

7 Una aportación interesante en este sentido es Didi-Huberman, 2007. 
Otro ejemplo de la feroz gestión biopolítica de la sexualidad femenina es la píldora anticonceptiva. En este sentido Preciado enuncia: "(...) la pildora opera desde el principio como una técnica no de control de la reproducción, sino de producción y control de género. La primera píldora inventada, aunque eficaz como control de natalidad, fue rechazada por el Instituto Americano de la Salud (AHI), porque, al suprimir totalmente las reglas, venía a poner en cuestión, según el comité científico, la feminidad de las mujeres americanas. Así se inventa una segunda píldora, igualmente eficaz, pero con una diferencia: su capacidad para reproducir técnicamente los ritmos de los ciclos menstruales naturales." (Preciado, 2008:133). La segunda píldora, a la que alude Preciado, fue la que se llegó a comercializar, convirtiéndose en uno de los medicamentos más rentables del siglo XX, y que ha llegado a nuestros días. Uno de los efectos secundarios más comunes de este medicamento es el descenso del deseo sexual, y aquí es donde interviene -o más bien, no interviene- la gestión biopolítica de la sexualidad femenina. En este sentido Preciado apunta: "Un estudio reciente llevado a cabo en la Universidad de Boston muestra la relación entre consumo de la píldora anticonceptiva, la baja de los niveles de biodisponibilidad de testosterona (se reduce entre un 40 y un 60 por 100) y la caída de la libido en mujeres. El equipo de la Universidad de Boston advierte que la utilización de estrógeno sintético puede modificar la producción, hormonal global. El mismo estudio propone la administración de testosterona en gel a bajas dosis para aumentar la función sexual en las mujeres consumidoras de la píldora. Sin embargo, la administración de testosterona para mujeres sigue siendo hoy un tabú hormonal de carácter político." (Preciado, 2008:135).

Otro momento histórico importante en la evolución de la sexualidad fue la aparición de la noción de género. Sorprendentemente, no surge de un ámbito de resistencia feminista, sino que nace en el seno de la clínica para categorizar los cuerpos intersexuales como patológicos y poder convertirlos en sujetos clínicos. Este concepto, que surge por una necesidad de reforzar la diferencia sexual binaria, paradójicamente se basa en la hipótesis, completamente constructivista, de que el género y la identidad sexual son modificables hasta la edad de 18 meses $^{8}$.

Casi al mismo tiempo, en 1949, Simone de Beauvoir publica El segundo sexo en el que cuestiona por primera vez la relación entre el sexo biológico y los roles sociales a través de su famoso enunciamiento: "no se nace mujer: se llega a serlo" (Beauvoir, 2005:113). El término género será planteado como una construcción social por primera vez en 1972 por Ann Oakley que lo definió como la construcción social y cultural de la diferencia sexual (Oakley, 1972). En 1981 Monique Wittig, integrada en la lucha feminista, retomará la idea de Simone de Beauvoir en su texto No se nace mujer. Esta autora concluye: "Simone de Beauvoir subrayó precisamente la falsa conciencia que consiste en seleccionar de entre las características del mito (que las mujeres son diferentes de los hombres) [...] supone no cuestionar radicalmente las categorías "hombre» y "mujer», que son categorías políticas (y no datos naturales)." (Wittig, 2006:36).

En El género en disputa, Judith Butler le da otra vuelta de tuerca a la construcción social del género, desarrollando la hipótesis de que no sólo se realiza un esfuerzo, más o menos consciente, por llegar a conseguir el rol de género que nos ha asignado la biología, sino que hay que mantenerlo a través de acciones cotidianas a lo largo de toda la vida. Esto le lleva a concluir que la identidad de género no es una condición inherente al humano sino que: "resulta ser performativo, es decir, que conforma la identidad que se supone que es. [...] no existe una identidad de género detrás de las expresiones de género; esa identidad se construye performativamente por las mismas "expresiones» que, al parecer, son resultado de ésta." (Butler, 1990:84).

Reinterpretando la frase de Simone de Beauvoir, Judith Butler diría: no se nace mujer, nunca se llega a serlo.

\section{Paul B. Preciado y el sistema farmacopornográfico}

El último autor que se menciona y que revisa tanto a Michael Foucault como a Judith Butler, entre otros, es Paul B. Preciado. Este filósofo sitúa dos procesos de industrialización del cuerpo sexual. El primero sucede a lo largo del siglo XIX en el que, como se ha dicho anteriormente, la sexualidad pasa de la esfera de lo privado para empezar a formar parte del dominio de lo público a través de una preocupación por la población. En sus propias palabras: "El objetivo de la biopolítica del siglo XIX es el control de la reproducción del cuerpo nacional se va a establecer una continuidad estricta entre sexualidad y reproducción, de manera que todas las prácticas no reproductivas serán consideradas como patológicas. A esa continuidad es a la que yo llamo primera industrialización de la sexualidad. [...] El artefacto biopolítico que resulta del establecimiento normativo de esa continuidad en beneficio de la reproducción del cuerpo nacional es, evidentemente, el cuerpo heterosexual." (Preciado, 2013).

Así mismo situará la segunda industrialización a partir de la Segunda Guerra Mundial a raíz de dos cambios: la invención de la noción de género y el desarrollo de un conjunto de técnicas endocrinológicas que van a separar la reproducción de la heterosexualidad (desarrollo de operaciones de cambio de sexo, fecundación in-vitro). En primer lugar desde la medicina la teoría de la diferencia sexual se ve cuestionada al considerar que el género se puede modificar hasta los dieciocho meses de edad. En segundo lugar la relación estrecha que se había establecido entre sexualidad y reproducción tendrá cada vez menos sentido. De esta manera Paul B. Preciado concluye: "No podemos seguir hablando de la clínica, como Foucault lo hacía pensando en la clínica del siglo XIX. Entre otras cosas porque, y esta será mi propuesta, el aparato de verificación, el conjunto de discursos, de representaciones, que permiten decir que un enunciado es verdadero o falso, y por tanto ya vais a ver que permiten afirmar la verdad del sujeto sexual han cambiado radicalmente. Mi propuesta es que el aparato de verificación neoliberal, ese que yo he llamado farmacopornografico contemporáneo, ya no es científico, sino que es mercantil y mediático. El aparato de verificación de la sexualidad contemporánea es el mercado y son los medios de comunicación" (Preciado, 2013).

8 En relación a este tema consultar Preciado, 2002:107. 


\section{CONCLUSIONES}

En cuanto a nivel teórico, la principal conclusión de la presente investigación es que la sexualidad es una construcción social compleja que aparece a finales del siglo XIX y que se instaura rápidamente en el imaginario colectivo, de tal manera que hoy en día la percibimos como algo ancestral e inmodificable. A pesar de que los aparatos de verificación que la regulan han variado notablemente en el último siglo, es posible advertir que tienen algo en común: el desarrollo y reproducción de modelos, que podrían identificarse como ejemplares, y que construyen y perpetúan una idea de normalidad. De esta manera podría decirse que la noción de sexualidad, siempre entendida desde el prisma contemporáneo occidental, está estructurada a partir de la idea lo normal; no pudiendo entender su complejidad sin tener en cuenta la relación que se establece entre ambos conceptos (sexualidad y normalidad).

Es importante subrayar que, dado que somos herederxs del heteropatriarcado, los sistemas de producción de sentido son, y siempre han sido, discriminatorios. Con esto quiero decir que la noción de normalidad que se establece desde los aparatos de verificación no es, ni mucho menos, neutra o imparcial. Lo que se entiende como 'normal' ha sido inventado y perpetuado, generalmente, por hombres blancos-de clase alta-cisgénero-heterosexuales; y después han existido una serie de colectivos que han luchado en contra de estos estándares y, con mayor o menor fortuna, han conseguido modificarlos. Hablo del feminismo, de la lucha negra, de los movimientos $\mathrm{LGTBIQ}+$ y un largo etcétera. No escribo esto como un alien que aterriza en un planeta desconocido. Lo escribo situando mi cuerpo en la lucha, atravesado por los discursos de estos colectivos. El machismo y el heterocentrismo han favorecido a una serie de sujetos y han marginalizado, patologizado e incluso criminalizado a muchos otros. Como se puede observar a lo largo del artículo, me interpelan especialmente las diferencias que se han establecido en la forma de vivenciar la sexualidad de los hombres y las mujeres. Podría decirse que el interés que me suscita esta cuestión es lo que me ha llevado a realizar esta investigación. Llevo tiempo preguntándome: ¿por qué en el imaginario colectivo está establecido que los hombres poseen un deseo sexual irrefrenable, y sin embargo las mujeres no? ¿Desde cuándo existe esta diferencia? Respecto a estas cuestiones puedo decir que, como hemos visto anteriormente, son construcciones sociales que aparecieron en el siglo XIX y que se mantienen hasta la actualidad. Debido a esto creo que es fundamental que uno de los horizontes de nuestra agenda política sea el desarrollo de una teoría de la sexualidad sana, despatologizada, libre de discriminaciones y que nos permita disfrutar libremente de nuestra vida sexual. Una teoría de la sexualidad, en definitiva, radical.

En cuanto a mis conclusiones personales, he podido constatar que la sexualidad es tremendamente importante en la vida de los sujetos, tanto a nivel individual como a nivel colectivo. La manera en la que somos capaces de gestionar nuestra vida sexual define en gran medida el curso del resto de ámbitos vitales. Esto genera muchos conflictos, debido a que nos vemos sometidos a una infinita cantidad de presiones que no nos permite disfrutar de nuestra sexualidad con libertad. A pesar de la llamada Revolución Sexual, después de realizar esta investigación, tengo la desesperanzadora impresión de que desde entonces se ha evolucionado muy poco en esta materia. Podría decir, incluso, que se ha retrocedido. Vivimos en un mundo completamente sexualizado en el que tenemos a nuestro alcance toda la información de la que queramos disponer $y$, sin embargo, el sexo sigue suponiendo el mismo tabú que hace cincuenta años. Hemos adoptado prejuicios y limitaciones que surgieron en el siglo XIX como naturales, sin cuestionarlos ni deconstruirlos. Si escuchamos a nuestro alrededor nos damos cuenta de que muchas cosas están fallando. Si tanteamos la superficie, observamos con cuidado las redes sociales y las producciones mass-media. Si analizamos los datos policiales de violaciones sexuales y de acoso sexual. Si preguntamos a los ginecólogos sobre qué les dicen los jóvenes cuando van a su consulta...Si hacemos todo esto, se percibe que, efectivamente, existen muchos problemas en este ámbito y que, casi con seguridad, no estamos siendo conscientes de la importancia que tiene esto.

\section{REFERENCIAS}

Baudrillard, Jean. 1970. La sociedad de consumo. Sus mitos, sus estructuras. Madrid: Editorial Siglo XXI.

Baudrillard, Jean. 1977. Cultura y simulacro. Barcelona: Editorial Kairós.

Bauman, Zygmunt. 2006. Vida líquida. Barcelona: Editorial Paidós.

Beauvoir, Simone de. 2005. El segundo sexo. Madrid: Editorial Cátedra.

Butler, Judith. 1990. El género en disputa. El feminismo y la subversión de la identidad. Barcelona: Editorial Paidós.

Córdoba, David. 2005. El contexto sociopolítico de surgimiento de la teoría queer. De la crisis del sida a Foucault. En Córdoba, David et al. (ed.) Teoría Queer. Políticas Bolleras, Maricas, Trans, Mestizas, 21-66. Madrid: Editorial Egales.

Debord, Guy. 1967. La sociedad del espectáculo. Valencia: Editorial Pre-textos.

Didi-Huberman, Georges. 2007. La invención de la histeria. Charcot y la iconografía fotográfica de la Salpètrière. Madrid: Editorial Anaya.

Foucault, Michael. 1988. Nietzsche, la genealogía, la historia. Madrid: Editorial Pre-textos.

Foucault, Michael. 1991. Historia de la sexualidad I. La voluntad del saber. Madrid: Editorial Siglo veintiuno.

Freud, Signmund. 2016. Tres ensayos sobre de Teoría Sexual. Paraguay. Editorial Amorrortu.

Gayle, Rubin. 1989. Reflexionando sobre el sexo: notas para una teoría radical de la sexualidad. En Canve, Carole S. (ed.) Placer y peligro. Explorando la sexualidad femenina, 113-190. Madrid: Editorial Revolución.

Haraway, Donna. 1997. Modest_Witness@Second_ Millenium.Female Man_Meets_Oncomouse. Feminism and Tecbnoscience. New York and London: Routledge. [Traducido al castellano en 2004. Testigo_Modesto@ Segundo_Milenio. HombreHembra_conoce_Oncoratón. Barcelona: Editorial IIOC].

Katz, Jonathan Ned. 2012. La invención de la heterosexualidad. Madrid: Editorial Ta Erotiká.

Kinsey, Alfred C. 1967. Conducta Sexual del Hombre. Buenos Aires: Siglo veinte.

Laqueur, Thomas W. 1994. La construcción del sexo. Cuerpo 
y género desde los griegos hasta Freud. Barcelona: Ediciones Cátedra.

Maines, Rachel P. 2010. La tecnología del orgasmo. La histeria, los vibradores, y la satisfacción sexual de las mujeres. Santander: Editorial Milrazones.

Masters, William H. y Johnson Virginia E. 1978. Respuesta sexual humana. Buenos Aires: Intermédica.

Oakley, Ann. 1972. Sex, gender and society. Londres: Editorial Harper Colophone Books.

OMS. 2002. Defining sexual health. Report of a technical consultation on sexual health: 28-31.

Preciado, Paul B. 2002. El manifiesto contra-sexual. Barcelona: Editorial Anagrama.

Preciado, Paul B. 2008. Testo Yonki. Madrid: Editorial Espasa.

Preciado, Paul B. 2013. ¿La muerte de la clínica?. Prácticas críticas. Somateca 2013. Vivir y resistir en la condición neoliberal, 09/03/2013. Madrid.

Querol, Ricardo de. 2016. Zygmunt Bauman: "Las redes sociales son una trampa". El País, 9/01/2016.

Royo, Alberto. 2017. La sociedad gaseosa. Barcelona: Editorial Plataforma.

Rubin, Gayle. 1986. El tráfico de mujeres: notas sobre la "economía política" del sexo. Nueva Antropología, 30 (3): 95-145.

Sontang, Susan. 1973. Sobre la fotografía. México DF: Editorial Alfaguara.

Stoller, Robert. 1968. Sex and Gender: On the Development of Masculinity and Femininity. Nueva York: Editorial Science House.

Weeks, Jefrey. 1998. Sexualidad. Mexico DF: Editorial Paidós.

Wittig, Monique. 2005. El pensamiento heterosexual y otros ensayos. Madrid: Editorial Egales.

Zizek, Slavoj. 2008. Sobre la violencia. Seis reflexiones marginales. Barcelona: Editorial Paidós. 